report can be negative: first the search strategy may be flawed and secondly no research may have been published. In the latter case this may be because the research question is novel or because the question being asked has been considered not worth answering.

We go to great lengths to ensure that the search strategies used are highly sensitive (particularly in the case of negative BETs) but recognise the limitations of Medline. We believe that by only seeking to answer questions that arise in clinical practice we avoid questions that are not worth answering. Thus negative BETs should identify novel research questions or highlight areas of clinical uncertainty.

It is therefore disappointing to see these negative BETs labelled as unhelpful, potentially misleading, or as a cause for misunderstanding. Rather they offer an opportunity for re-examining our ideas about the treatment of these conditions, and allow us to decide whether well designed studies that really answer the questions posed are needed.

1 Carley S, Mackway-Jones K (Mackway-Jones K, ed). Collar and cuff or sling after fracture of the clavicle. $₹$ Accid Emerg Med 1999;16:140.

2 Herren K, Carley S (Mackway-Jones K, ed) Support for uncomplicated shaft of humerus Support for uncomplicated shaft of hum

3 Carley SD, Mackway-Jones K, Jones A, et al. Carley SD, Mackway-Jones $\mathrm{K}$, Jones $\mathrm{A}$, et al.
Moving towards evidence based emergency medicine: use of a structured critical appraisal journal club. $\mathcal{F}$ Accid Emerg Med 1998;15:220-2.

4 Mackway-Jones K, Carley SD, Morton RJ, et al The best evidence topic report: a modified CAT for summarising the best evidence in emergenc medicine. F Accid Emerg Med 1998;15:222-6.

\section{Management of minor head injuries by non-specialists}

EDITOR,-The management of patients with a minor head injury (MHI)-that is a Glasgow coma scale score of $13-15,{ }^{1}$ once the decision has been made to admit them, is relatively simple and straightforward. The value of having neurosurgical specialist input could be looked upon as a luxury. In Nottingham there is a co-located accident and emergency (A\&E) department with a regional neurosurgical unit. It is often the case that the A\&E beds for observation become full and the local arrangement is for the regional neurosurgical unit to admit the patient under their care. The use of this resource for this condition has been questioned and a retrospective review of patients with a MHI admitted to this hospital was undertaken to determine the actual involvement of neurosurgery in the management of these cases in a typical teaching hospital.

For the calendar year of 1996, 618 adults (>16 years of age) were admitted with a diagnosis of MHI for observation, of whom 89 (14.4\%) were referred to the regional neurosurgical unit (M:F = 63:26; 70.8\%:29.2\%). Thirty seven $(42 \%)$ had other injuries, some of which would have required admission in any case, for example maxillofacial or spinal fracture in eight $(9 \%)$, their MHI being truly minor.

The A\&E referral was made because of no A\&E beds in 47 (53\%), was not stated at all on the admission card in $22(25 \%)$, was for "social reasons" in four (4\%), and in two (2\%) was because they had been under a neurosurgeon some years previously for totally unrelated conditions. Only two of $24(8 \%)$ patients who had a computed tomography during their admission had anything abnormal detected, neither of whom needed any intervention beyond simple observation.
The same survey carried out in the same hospital in the year 1992 revealed, using a randomly acquired sample of 90 patients with MHI, that eight ( $9 \%$ ) were referred to the regional neurosurgical unit, none of whom needed any active intervention.

One of the authors (NB) carried out a similar review of patients admitted under general surgeons with MHI for the year 1991 in a different large general hospital with a co-located A\&E department (at that time a trial trauma centre) and subregional neurosurgical unit. Of 53 patients admitted with MHI only four ( $7.5 \%)$ required a neurosurgical opinion and none required active intervention.

These three temporally separate studies in two different, but similar, hospitals found a total of 761 patients admitted with $\mathrm{MHI}$, none of whom required neurosurgery. It is our contention that no patients with MHI need be admitted under the care of neurosurgeons in this country and that patients who need specialist neurosurgical input can be identified by neurological observations in a nonspecialist setting and referred for advice or action accordingly.

HENRY PAU

NEIL BUXTON

Department of Neurosurgery,

University Hospital, Nottingham NG7 2UH

1 Miller JD. Minor, moderate and severe head injury. Neurosurg Rev 1986;9:135-9. accident and emergency staff

EDITOR,-Birkinshaw et al have recently demonstrated that in reconstructed scenarios using manikins, $80 \%$ of estimates of blood loss by paramedics and technicians were underestimates, and for a blood loss of 3 litres the mean underestimate was $60 \% .^{1}$ It is also important that staff in the accident and emergency (A\&E) department can assess blood loss that is continuing within the department and also assess loss in clothing as it is removed, as is stressed in Advanced Trauma Life Support courses. ${ }^{2}$

We undertook a study whereby a measured volume $(450 \mathrm{ml})$ of expired human whole blood was spilt over some clothing on a non-absorbent surface. After five minutes this scene was photographed. The photograph was shown to staff of the A\&E department and they were asked to estimate the volume of blood shown in the photograph.

Forty $A \& E$ nurses and 18 senior house officers (SHOs) were surveyed. Their estimates of blood loss are shown in table 1.

This demonstrates that staff in A\&E show a wide variation in the accuracy of their estimations of blood loss and it is not reliable for clinical decision making. In contrast to the pre-hospital study, A\&E staff appear to overestimate blood loss. None of the staff had ever been shown pictures of measured blood loss as part of their training. There is a need to train A\&E staff in the assessment of external blood loss.
Visual assessment of blood loss by

JEREMY HARRISON

Specialist Registrar in Accident and Emergency, City Hospital, Birmingham MATTHEW W COOKE Senior Lecturer in Emergency Care, Emergency Medicine Research Group, University of Warwick and Walsgrave Hospitals NHS Trust

(Correspondence to: Dr Cooke, PO Box 3999, Knowle, Solihull $B 938 Q Q$

1 Birkinshaw R, Zahir M, Ryan B. Visual assessment of blood loss at the accident scene. Pre-hospital Immediate Care 1998;2:197-8.

2 American College of Surgeons. Advanced traume life support for doctors. 6th Ed. Chicago: ACS, 1997.

Transtracheal jet ventilation and the completely obstructed airway: incorporating an active expiratory phase

EDrToR,-Transtracheal jet ventilation is an important technique in emergency airway management. During an audit of equipment available for emergency airway management we had occasion to test various devices for transtracheal jet ventilation on a model trachea and lung (BOC Lung Ventilator Performance Analyser, compliance $50 \mathrm{ml} / \mathrm{cm} \mathrm{H}_{2} \mathrm{O}$ ) with an interposed Wright respirometer to measure minute ventilation. Using a 14 gauge cannula and Sander's injector connected to a $400 \mathrm{kPa}$ oxygen outlet in a model where the "laryngeal" end of the "trachea" was completely obstructed, further ventilation following the first insufflation was clearly not possible without hyperinflation of the model lung.

In this situation where expiration via the natural airway is not possible, it is a commonly believed myth that insertion of another 14 gauge cannula will allow the lungs to deflate between insufflations. In our model, when this was performed, a minute ventilation of 2.5 $1 / \mathrm{min}$ was achieved. This is clearly insufficient for adequate ventilation for any considerable length of time. However, when the expiratory cannula was connected to standard wall suction set at "high" $(80 \mathrm{kPa})$, a minute ventilation of $10 \mathrm{l} / \mathrm{min}$ was consistently achieved. A similar result was obtained using only one cannula connected to the Sander's injector and suction via a three way tap alternating between the two for inspiration and expiration.

This technique has not been tried in clinical practice and it is possible that the expiratory phase could become obstructed by tracheal mucosa, blood, or mucus. However, in the situation of a completely obstructed airway where a satisfactory needle cricothyroidotomy for transtracheal jet ventilation has been performed incorporation of an active expiratory phase may allow a clinically useful minute ventilation and would remove to some degree the time pressure before a more satisfactory definitive airway (for example surgical cricothyroidotomy) is achieved.

G KESSELL

Consultant Anaesthetist, Cleveland School of Anaesthesia, Cheriton House, South Cleveland Hospital, Marton Road, Middlesbrough TS4 3BW

Table 1 AEE staff's estimate of volume of a measured $450 \mathrm{ml}$ blood loss

\begin{tabular}{lllllll}
\hline & No surveyed & Mean & Maximum & Minimum & 1st quartile & 3rd quartile \\
\hline Nurse & 40 & 577.6 & 3000 & 50 & 200 & 681 \\
SHO & 18 & 633.9 & 2500 & 30 & 250 & 575
\end{tabular}

